
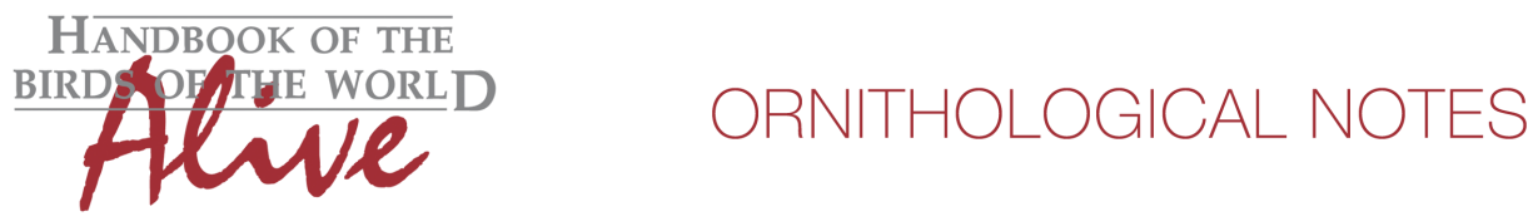

\title{
Notes on the vocalizations of Bicoloured Antbird (Gymnopithys leucaspis)
}

Peter Boesman

In the following we briefly analyze and compare voice of the different races of Bicoloured Antbird (Gymnopithys leucaspis). We also try to quantify the extent of any vocal differences using the criteria proposed by Tobias et al. (2010), as a support for taxonomic review. We have made use of sound recordings available on-line from Xeno Canto (XC).

As an introductory remark, it should be said that the loudsong and calls of many antfollowing antbirds are quite similar (It wouldn't be surprising that this is an adaptation to efficiently communicate the location of army ant swarms among these species). Also, there is quite some variability in the song depending on the level of excitement.

We have compared the loudsong of all races of $G$. leucaspis by dividing them into two groups: races occurring West of the Andes (olivascens, bicolor, daguae, aequatorialis, ruficeps) and East of the Andes (leucaspis, castaneus, lateralis and peruanus).

$\begin{array}{ll}\text { Group 1: West of Andes (Central America and Chocó region) ( } \mathrm{n}=10 \\ \text { total length } & 2.88-3.70 \mathrm{~s} \\ \text { \# of notes } & 13-26 \\ \text { max. freq. } & 4200-5040 \mathrm{~Hz} \\ \text { lowest max. freq. } & 2400-3500 \mathrm{~Hz} \\ \text { first note length } & 0.18-0.29 \mathrm{~s} \\ \text { max. pace* } & 0.085-0.14 \\ \text { max. length harsh note } & 0.21-0.28 \text { (present in } 75 \% \text { of songs) } \\ \text { average pace } & 0.14-0.22\end{array}$

( $*$ pace is measured here as period, the duration between 2 subsequent notes)

Group 2: Amazon region $(n=8)$

total length

\# of notes

max. freq.

lowest max. freq.

first note length

max. pace

max. length harsh note

average pace

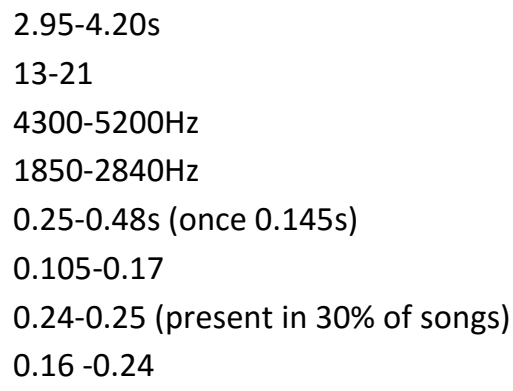

It is clear that differences in the basic sound parameters of loudsong are very small. Birds of group 1 tend to have a shorter first note (with considerable overlap, score $0-1$ ), tend to reach the highest level of acceleration (with considerable overlap, score $0-1$ ) and use more often harsh notes as an end to the song (score 0-1)(Fig. 1).

Total score about 1-2. 


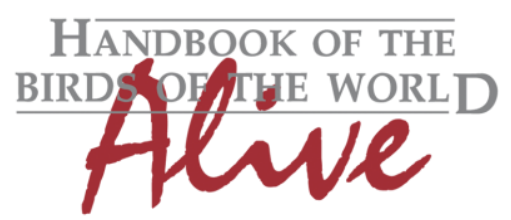

\section{ORNITHOLOGICAL NOTES}
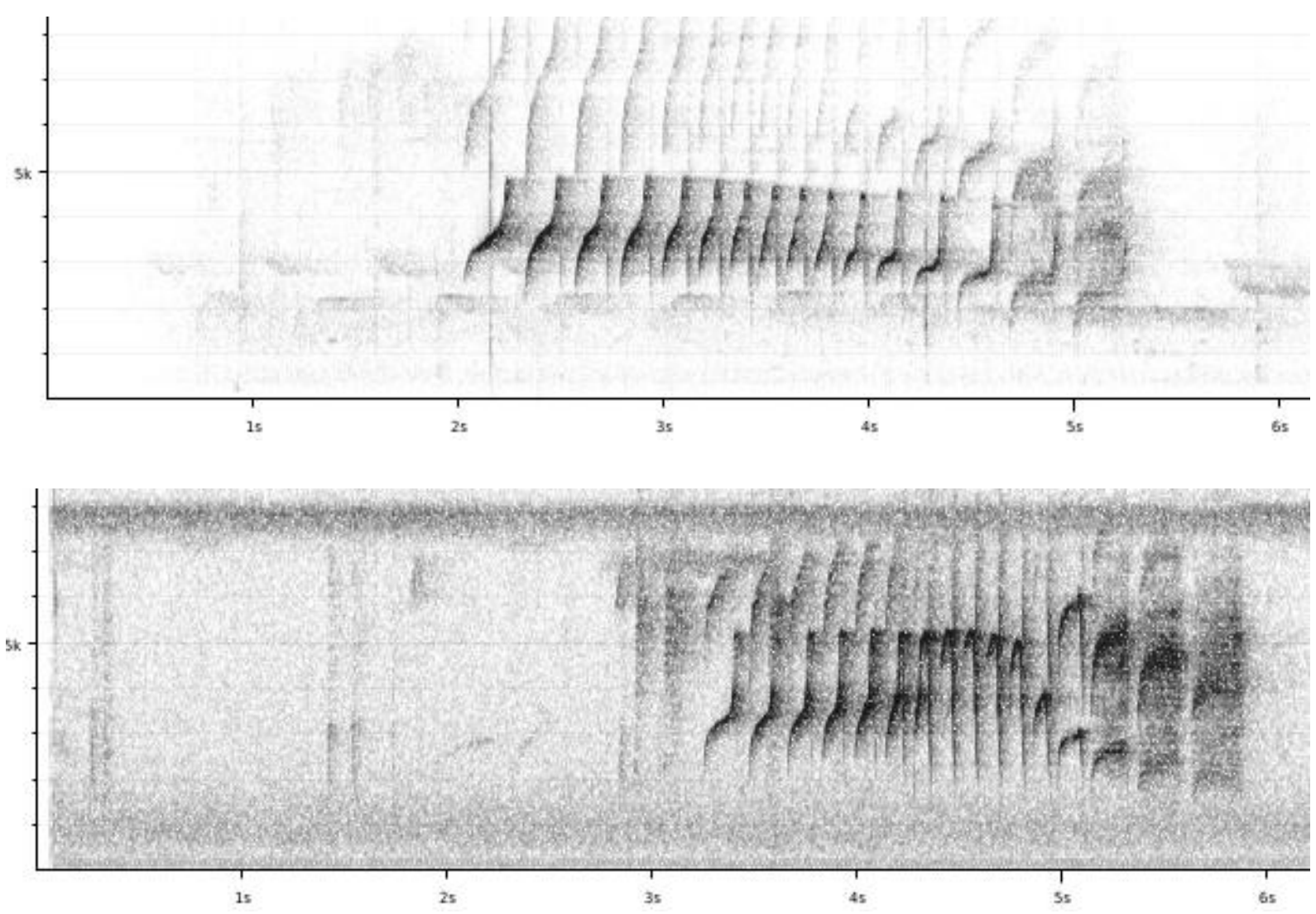

Figure 1: top to bottom: typical loudsong of group 1 (Panama) and group 2 (E Ecuador)

It would thus seem that the difference in loudsong is smaller than has been suggested in the past (Zimmer 2003).

While difference in loudsong has been used as an important criterion for redefining taxonomy in Antbirds, in some cases (e.g. Hypocnemis) call notes have been the main vocal driver. We therefore also compared the main call of the 2 groups:

\section{Measurements of the long churr call}

Group 1: West of Andes (Central America and Chocó region) ( $n=9)$

total length

max. freq.

min. freq.

freq. range
$0.55-0.75 \mathrm{~s}$

$1690-3200 \mathrm{~Hz}$ (once $3900 \mathrm{~Hz}$ )

$820-1290 \mathrm{~Hz}$

$830-2200 \mathrm{~Hz}$

Group 2: Amazon region $(n=8)$

total length

max. freq.

min. freq.

freq. range
$0.40-0.59 s$

$3100-4700 \mathrm{~Hz}$

$780-1290 \mathrm{~Hz}$

$2320-3640 \mathrm{~Hz}$ 

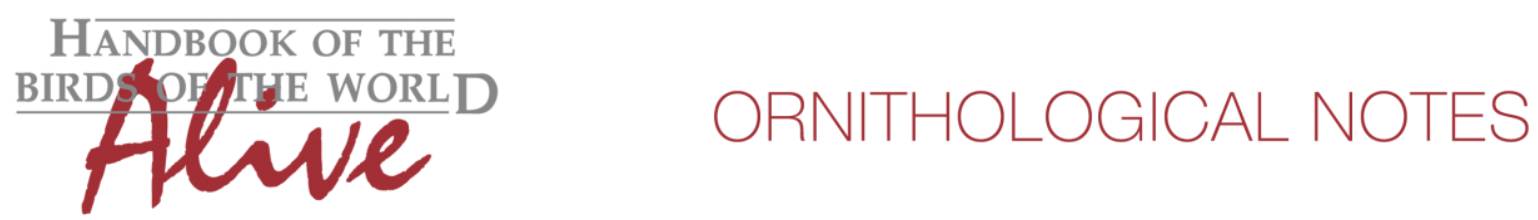

Here there seems to be a clear difference:

Birds of group 1 tend to have a longer churring call (score 1-2), which has usually a lower max. frequency (score 1-2) and a smaller overall frequency range (score 2) (Fig. 2). If we consider max. freq. and freq. range as independent variables, this would lead to a score of 3-4.

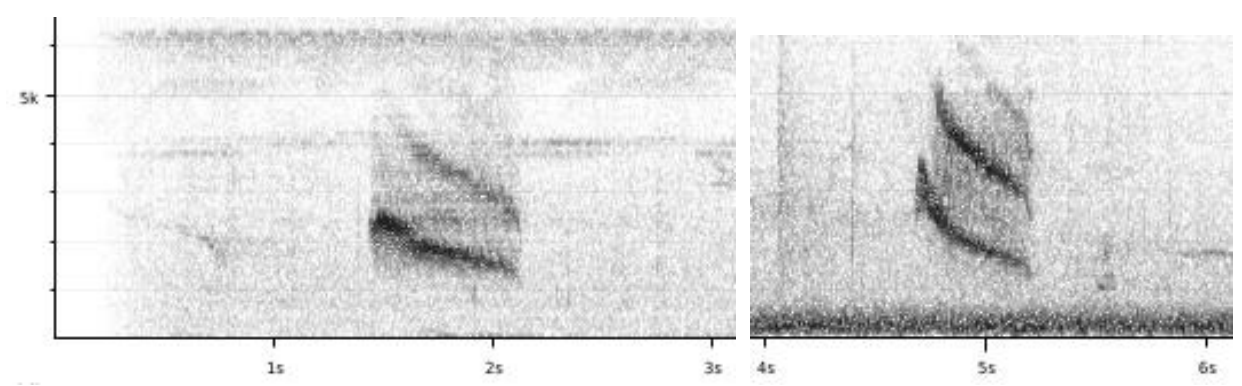

Figure 2: from left to right typical churring call of group 1 (NW Ecuador) and group 2

This quick analysis shows that the best way to tell voice apart is actually the churring call (total score 3-4), while the loudsong only shows minor differences which would need a more in depth statistical approach to determine any consistent differences, but for which one can predict that score will probably be 2 or less.

This note was finalized on 29th June 2015 , using sound recordings available on-line at that moment. We would like to thank in particular the sound recordists who placed their recordings for this species on XC: Nick Athanas, Peter Boesman, Tayler Brooks, Jerome Fischer, David Geale, Olaf Jahn, Niels Krabbe, Dan Lane, Gabriel Leite, Alex Lees, Jeremy Minns, John V. Moore, Mike Nelson, Jonas Nilsson, Andrew Spencer, Tom Will, Sam Woods.

\section{References}

Tobias, J.A., Seddon, N., Spottiswoode, C.N., Pilgrim, J.D., Fishpool, L.D.C. \& Collar, N.J. (2010). Quantitative criteria for species delimitation. Ibis 152(4): 724-746.

Zimmer, K. and M. Isler. 2003. Family Thamnophilidae (typical antbirds). Pages 448-681 in J. del Hoyo, A. Elliot, and D. A. Christie, editors. Handbook of the Birds of the World. Vol. 8. Broadbills to Tapaculos. Lynx Edicions, Barcelona. 


\section{Recommended citation}

Boesman, P. (2016). Notes on the vocalizations of Bicoloured Antbird (Gymnopithys leucaspis). HBW Alive Ornithological Note 59. In: Handbook of the Birds of the World Alive. Lynx Edicions, Barcelona. (retrieved from http://www.hbw.com/node/931941 on 14 May 2016). 